ARTICLE

https://doi.org/10.1038/s41467-020-18188-z

\title{
OPEN
}

\section{Regioselective functionalization of aryl azoles as powerful tool for the synthesis of pharmaceutically relevant targets}

\author{
Ferdinand H. Lutter (1) ${ }^{1}$, Lucie Grokenberger ${ }^{1}$, Luca Alessandro Perego (1) 2, Diego Broggini², \\ Sébastien Lemaire (iD ${ }^{3}$, Simon Wagschal (i) ${ }^{2 \otimes} \&$ Paul Knochel (i) ${ }^{1 凶}$
}

Aryl azole scaffolds are present in a wide range of pharmaceutically relevant molecules. Their ortho-selective metalation at the aryl ring is challenging, due to the competitive metalation of the more acidic heterocycle. Seeking a practical access to a key Active Pharmaceutical Ingredient (API) intermediate currently in development, we investigated the metalation of 1aryl-1H-1,2,3-triazoles and other related heterocycles with sterically hindered metal-amide bases. We report here a room temperature and highly regioselective ortho-magnesiation of several aryl azoles using a tailored magnesium amide, $\mathrm{TMPMgBu}(\mathrm{TMP}=2,2,6,6$-tetramethylpiperidyl) in hydrocarbon solvents followed by an efficient Pd-catalyzed arylation. This scalable and selective reaction allows variation of the initial substitution pattern of the aryl ring, the nature of the azole moiety, as well as the nature of the electrophile. This versatile method can be applied to the synthesis of bioactive azole derivatives and complements existing metal-mediated ortho-functionalizations.

\footnotetext{
${ }^{1}$ Ludwig-Maximilians-Universität München, Department Chemie, Butenandtstrasse 5-13, Haus F, 81377 München, Germany. ${ }^{2}$ Discovery Product Development and Supply, Janssen Pharmaceutica, Hochstrasse 201, 8200 Schaffhausen, Switzerland. ${ }^{3}$ Discovery Product Development and Supply, Janssen Pharmaceutica, Turnhoutseweg 30, B-2340 Beerse, Belgium. ${ }^{凶}$ email: swagscha@its.jnj.com; paul.knochel@cup.uni-muenchen.de
} 
N -aryl azole scaffolds are present in several marketed and experimental drugs, such as celecoxib ${ }^{1}$, apixaban ${ }^{2}$, zibotentan $^{3}$, and nesapidil ${ }^{4}$ (Fig. 1a). As part of an ongoing development program, we sought a straightforward access to $\mathrm{N}$ aryl-1,2,3-triazole $1 \mathbf{a}^{5}$. An attractive and efficient approach to access such heterocyclic motif is the $\mathrm{C}-\mathrm{H}$ functionalization of 1aryl-1H-1,2,3-triazoles such as 2 a (Fig. 1b). A well-established strategy involves transition metal-catalyzed $\mathrm{C}-\mathrm{H}$ arylations $s^{6-21}$. These reactions usually require harsh conditions and often lead to bis-arylated products, which limits their practicality,8,12-17,22,23 . The direct deprotonation with a suitable base may be an alternative for the selective functionalization of aryl azoles. However, the regioselective metalation of the aryl ring linked to a heterocycle is challenging, due to the competitive and often favored metalation of the $N$-heterocycle itself ${ }^{24}$.

A potential approach to achieve a regioselective metalation at the aryl ring is the avoidance of coordinating solvents such as THF, which competes with the nitrogen atom of the azole ring in complexation of the base ${ }^{25}$. Sterically hindered metal-amide bases, especially magnesium- and zinc-derived TMP-bases (TMP $=2,2,6,6$-tetramethylpiperidyl) have proved to be powerful reagents for the functionalization of various (hetero)arenes ${ }^{26-33}$. The use of hindered metal amides in hydrocarbon solvents should thus be beneficial. In line with this concept, Hagadorn showed that $\mathrm{TMP}_{2} \mathrm{Zn}$ is an excellent base for the $\alpha$-zincation of various carbonyl compounds and the metalation of pyridine- $\mathrm{N}$-oxide in toluene ${ }^{34,35}$. Similarly, Mulvey and co-workers ${ }^{36-43}$ reported several mixed bimetallic amide bases for metalation reactions in non-coordinating hydrocarbon solvents. Herein we report a highly selective and broadly applicable magnesiation of various aryl azoles using the amide base TMPMgBu in a toluene/hexane solvent mixture and subsequent cross-couplings and electrophilic quench reactions.

\section{Results}

Reaction optimization. In preliminary experiments, the reaction of 1-aryl-1H-1,2,3-triazole $\mathbf{2 a}$ with various metal-amide bases was examined to assess the selectivity between products $\mathbf{A}$ and $\mathbf{B}$. The use of strong bases like TMPLi or LDA exclusively afforded the undesired metalation at the most acidic 5-position of the triazole together with large amounts of decomposition products (Fig. 2a, entries 1-2). Similarly, mixtures of $\mathbf{A}$ and $\mathbf{B}$ were obtained with TMPMgCl$\cdot \mathrm{LiCl}$ or $\mathrm{TMP}_{2} \mathrm{Mg}$ in $\mathrm{THF}^{44-46}$ (entries 3-4). We turned our attention to TMPMgBu${ }^{47,48}$, which was conveniently prepared by treating TMP- $\mathrm{H}$ with commercially available $\mathrm{Bu}_{2} \mathrm{Mg}$ in hexane $\left(25^{\circ} \mathrm{C}, 48 \mathrm{~h}\right)$, affording a clear $0.74-0.81 \mathrm{~m}$ solution in 94-98\% yield (Fig. 2b). Unfortunately, performing the metalation of $\mathbf{2 a}$ in THF using TMPMgBu did not yield better results in terms of selectivity between the two metalation sites (Fig. 2a, entry 5). As mentioned above, we anticipated that the use of the highly coordinating solvent THF could hamper a selective coordination at the $\mathrm{N}(2)$-atom of the triazole. We therefore switched to metal bases in hydrocarbons. While $\mathrm{TMP}_{2} \mathrm{Mg}$ in toluene proved to be too reactive, leading to extensive decomposition of the starting material $\mathbf{2 a}$ (entry 6), TMPMgBu in toluene turned out to be highly selective, affording the desired metalated triazole $\mathbf{A}$ in $81 \%$ yield within $1 \mathrm{~h}(\mathbf{A}: \mathbf{B}=96: 4$, entry 7$)$. However, $\mathrm{TMP}_{2} \mathrm{Zn}^{34,35}$ or $i \mathrm{PrMgCl} . \mathrm{LiCl}$ were not suitable reagents for the deprotonation of the aryl moiety of $2 \mathbf{a}$ (entries 8-9).

Substrate scope. We then examined the reactivity of the arylmetal species generated via deprotonation with $\mathrm{TMPMgBu}$ in the palladium-catalyzed Negishi cross-coupling (Fig. 2c). After transmetalation with $\mathrm{ZnCl}_{2}$, the resulting arylzinc reagent was coupled with 4-chloro-6-methoxypyrimidine using $1 \mathrm{~mol} \%$ of $\left[\mathrm{PdCl}_{2}(\mathrm{dppf})\right]\left(\mathrm{dppf}=1,1^{\prime}\right.$-bis(diphenylphosphino)ferrocene) and the desired active pharmaceutical ingredient (API) intermediate 1a could be isolated in $86 \%$ yield. With these results in hand, we examined the scope of the metalation reaction using various substituted aryl triazoles (Fig. 3).

The metalation of the electron-deficient triazole $\mathbf{2} \mathbf{b}$ proceeded smoothly within $1 \mathrm{~h}$ at room temperature leading exclusively to the organomagnesium reagent $3 \mathbf{b}$ in $86 \%$ yield. The unsubstituted phenyl derivative $2 \mathrm{c}$ was metalated in $4 \mathrm{~h}$ affording $72 \%$ of the desired metal reagent $3 \mathrm{c}$ along with $6 \%$ deprotonation at the triazole 5-position. The electron-rich triazoles $2 \mathbf{d}-\mathbf{f}$ required a prolonged metalation time of $4-6 \mathrm{~h}$ and furnished $3 \mathbf{d}-\mathbf{f}$ in $68-77 \%$ yield. The metalation of the ortho-fluoro triazole $2 \mathrm{~g}$
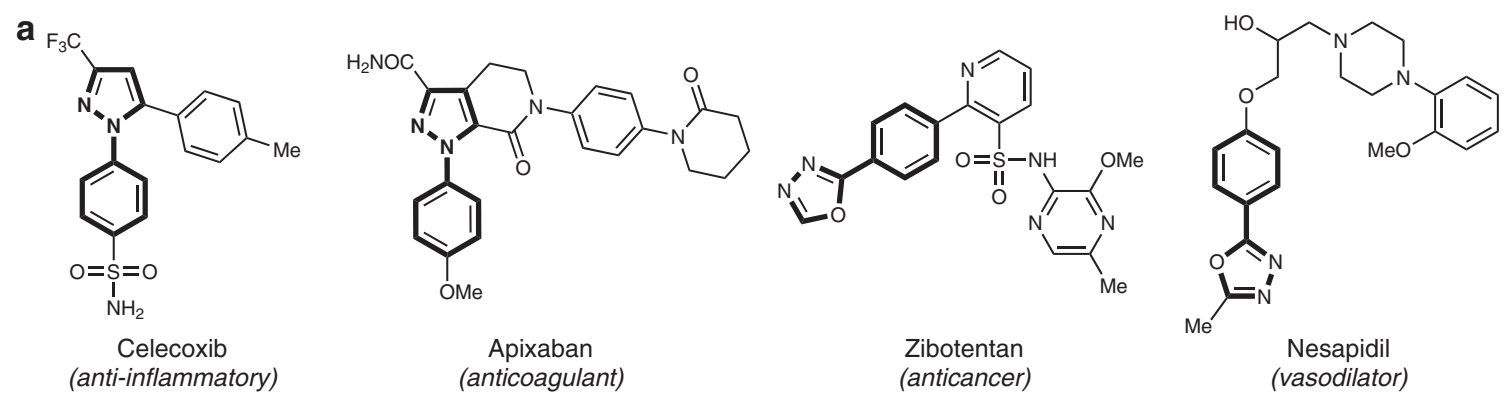

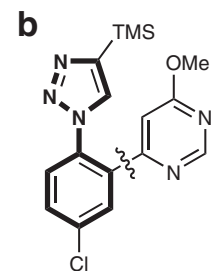

1 a

Key $A P I$

intermediate

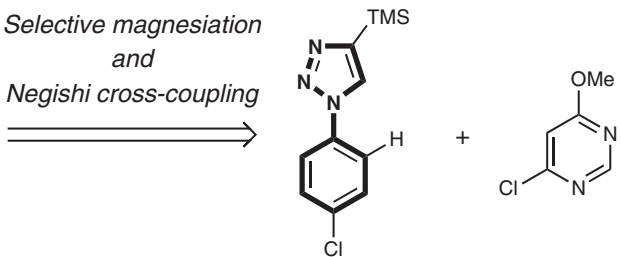

$2 a$

Fig. 1 Background and objective. a Examples of bioactive aryl azole derivatives. b Retrosynthetic strategy for API intermediate 1a. 
a<smiles>CS(=O)(=O)c1cn(-c2ccc(Cl)cc2)nn1</smiles>

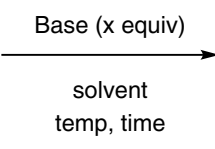

$2 a$<smiles>CS(=O)(=O)c1cn(-c2ccc(Cl)cc2[N+]#N)nn1</smiles>

A<smiles>CS(=O)(=O)c1nnn(-c2ccc(Cl)cc2)c1C#N</smiles>

B

\begin{tabular}{|c|c|c|c|c|c|c|c|}
\hline Entry & Base & Equiv & Solvent & Time $[\mathrm{h}]$ & Temp & $A^{[a]}$ & $\mathbf{B}^{[\mathrm{a}]}$ \\
\hline 1 & TMPLi & 1.2 & THF & 0.5 & $-78^{\circ} \mathrm{C}$ & $0 \%$ & $35 \%[b]$ \\
\hline 2 & LDA & 1.2 & THF & 0.5 & $-78^{\circ} \mathrm{C}$ & $0 \%$ & $40 \%[c]$ \\
\hline 3 & TMPMgCl'LiCl & 1.2 & THF & 1 & rt & $39 \%$ & $19 \%$ \\
\hline 4 & $\mathrm{TMP}_{2} \mathrm{Mg}$ & 1.2 & THF & 1 & $\mathrm{rt}$ & $67 \%$ & $23 \%$ \\
\hline 5 & TMPMgBu & 1.2 & THF & 1 & $r t$ & $78 \%$ & $40 \%[d]$ \\
\hline 6 & $\mathrm{TMP}_{2} \mathrm{Mg}$ & 1.2 & Toluene & 1 & rt & \multicolumn{2}{|c|}{ Decomposition } \\
\hline 7 & TMPMgBu & 1.0 & Toluene & 1 & rt & $81 \%$ & $3 \%$ \\
\hline 8 & $\mathrm{TMP}_{2} \mathrm{Zn}$ & 1.0 & Toluene & 1 & rt & $0 \%$ & $2 \%$ \\
\hline 9 & IPrMgCl'LiCl[e] & 1.0 & Toluene & 1 & rt & $7 \%$ & $3 \%$ \\
\hline
\end{tabular}

b

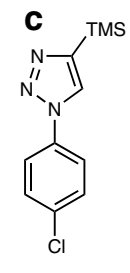

$2 a$

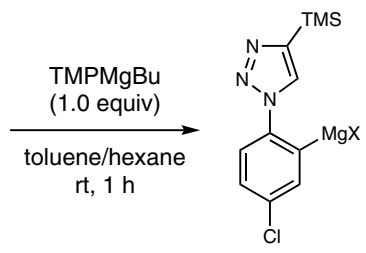

3 a $81 \%[a]$

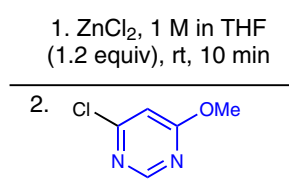

(2.1 equiv)

$\left[\mathrm{PdCl}_{2}\right.$ (dppf)] (1.0 mol\%) $55^{\circ} \mathrm{C}, 18 \mathrm{~h}$

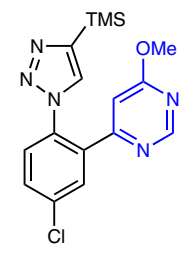

1a $86 \%$

Key API

intermediate

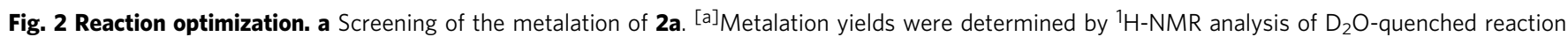
aliquots. [b]Sixty-five percent decomposition. ${ }^{[\mathrm{c}]}$ Forty-three percent decomposition. [d] Including bis-metalated species. ${ }^{[\mathrm{e}]}$ In THF. $\mathbf{b}$ Preparation of TMPMgBu. c Pd-catalyzed cross-coupling reaction towards $\mathbf{1 a}$.

afforded $\mathbf{3 g}$ in $80 \%$ yield. We did not observe any metalation ortho to either the methoxy or the fluoro moieties, indicating that the triazole unit is a much stronger directing group than those substituents. When testing other substituents at the 4-position of triazole, we found that the TMS group was key to reach high selectivity as the corresponding 4-butyl and 4-phenyl analogs afforded only mixtures of arylmagnesium species (see Supplementary Fig. 13).

Magnesium organometallics $\mathbf{3 a}-\mathbf{g}$ were then transmetalated with $\mathrm{ZnCl}_{2}$ prior to their use in the cross-coupling with a variety of functionalized (hetero)aryl bromides. Palladium-catalyzed coupling reactions proceeded smoothly with several electron-rich and -deficient aryl bromides, furnishing the corresponding products $\mathbf{1 b}-\mathbf{f}$ in $75-87 \%$ yield. Remarkably, the reaction of the sterically demanding 2-bromonaphthalene led to $\mathbf{1 g}$ in $74 \%$ yield. Various fluorinated aryl bromides containing a trifluoromethoxy, pentafluorosulfinyl, trifluoromethyl, or fluoro substituent were successfully applied in these couplings affording the desired arylated products $\mathbf{1 h}-\mathbf{k}$ in $70-95 \%$ yield. Furthermore, a range of heteroaryl bromides, such as pyridyl-, pyrimidyl-, indolyl-, and various thienyl- and furyl bromides were used as coupling partners leading to the corresponding products $11-s$ in $62-96 \%$ yield. Next, the metalation was extended to other aryl azoles (Fig. 4a). Treating 1phenyl-3,5-dimethyl-1H-pyrazole 4a with TMPMgBu (1.0 equiv) for $1 \mathrm{~h}$ afforded $\mathbf{5 a}$ in $82 \%$ yield and perfect regioselectivity. Unsubstituted pyrazole $\mathbf{4 b}$ was selectively metalated at the aryl moiety leading to the magnesium reagent $\mathbf{5 b}$ (78\% yield). Remarkably, no competitive metalation of the azole ring was observed in any case. Furthermore, 2,5-diphenyl-1,3,4-oxadiazole $4 \mathrm{c}$ underwent a selective mono-magnesiation, affording $5 \mathrm{c}$ in $76 \%$ yield after $2 \mathrm{~h}$ metalation time. The magnesiation of phenyl oxazoline $4 \mathbf{d}$ proceeded within $1 \mathrm{~h}$ leading to the metalated product $\mathbf{5 d}$ in $77 \%$ yield.

Negishi cross-couplings starting from 5a afforded the compounds $\mathbf{6 a}-\mathbf{b}$ in $68-95 \%$ yield under the standard conditions.
Substrates containing such a 3,5-dimethylpyrazole group are of special interest, since an oxidative cleavage via ozonolysis affords the corresponding $N$-acetylated anilines ${ }^{17}$. The unsubstituted $N$ aryl pyrazolylmagnesium reagent $\mathbf{5 b}$ was coupled with functionalized aryl bromides bearing a tosylate and nitrile group leading to the products $\mathbf{6 c}-\mathbf{d}$ in $89 \%$ and $88 \%$ yield, respectively. The reaction of $5 \mathrm{c}$ with bromobenzene afforded the corresponding $1,3,4$-oxadiazole $\mathbf{6 e}$ in $80 \%$ yield, which is a valuable precursor for the synthesis of electroluminescent compounds ${ }^{49}$.

Additionally, a more electron-deficient derivative was synthesized following the optimized procedure leading to $6 \mathbf{f}$ in $75 \%$ yield. Finally, the cross-coupling of $\mathbf{5 d}$ furnished the corresponding products $\mathbf{6 g}-\mathbf{h}$ in $91-96 \%$ yield.

The versatility of the method was shown by performing various trapping reactions of the arylmagnesium reagent $3 \mathbf{a}$ with several commonly used electrophiles (Fig. $4 \mathrm{~b}$ ). Thus, a reaction with $\mathrm{I}_{2}$ afforded $7 \mathbf{a}$ in $98 \%$ yield and the addition of benzaldehyde or $\mathrm{MeSSO}_{2} \mathrm{Me}$ to $\mathbf{3 a}$ led to the corresponding alcohol $\mathbf{7 b}$ or thioether $7 \mathrm{c}$ in $86 \%$ and $75 \%$ yield, respectively. A transmetalation with $\mathrm{CuCN} \cdot 2 \mathrm{LiCl}$ and subsequent reaction with benzoyl chloride or an allyl bromide derivative afforded $7 \mathbf{d}-\mathbf{e}$ in $62-77 \%$ yield.

Late-stage diversification. Various late-stage modifications were performed to demonstrate the synthetic utility of the crosscoupling products (Fig. 5). The TMS group could be easily removed using TBAF giving access to unsubstituted triazole 8 in $91 \%$ yield. Treating $\mathbf{1 h}$ with TMPMgBu for $2 \mathrm{~h}$ in toluene led to the arylmagnesium reagent 9 in $80 \%$ yield. After transmetalation with $\mathrm{ZnCl}_{2}$, a palladium-catalyzed cross-coupling with 5-bromo$\mathrm{N}$-methyl indole afforded the bis-arylated triazole $\mathbf{1 0}$ in $88 \%$ yield. The reaction of $\mathbf{1 h}$ with 1,3-dibromo-5,5-dimethylhydantoin furnished the corresponding bromide 11 in $93 \%$ yield. A palladium-catalyzed Suzuki-cross-coupling of $\mathbf{1 1}$ with an arylboronic acid allows the smooth functionalization of the triazole moiety, affording 12 in $86 \%$ yield. 


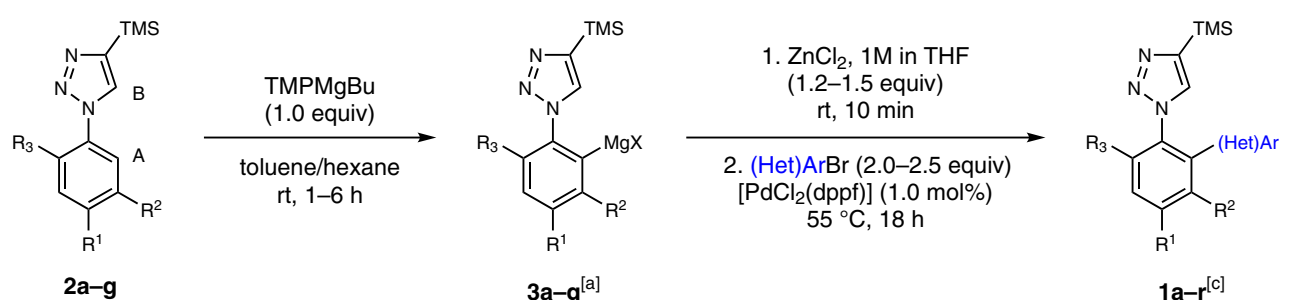

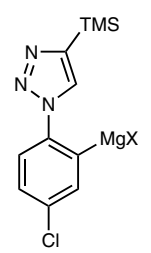

3a $81 \%(1 \mathrm{~h})$

$A: B=96: 4$

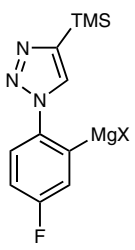

3b $86 \%$ (1 h)

$A: B=>99: 1$

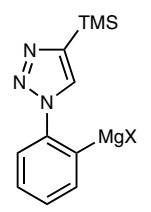

3c $72 \%(4 \mathrm{~h})$
$A: B^{[b]}$<smiles>[X]c1ccc(-n2cc(C)nn2)c([N+](=O)[O-])c1</smiles>

3d $68 \%(6 \mathrm{~h})$

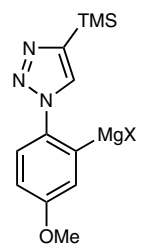

3e $77 \%$ (4 h)

$\mathrm{A}: \mathrm{B}=>99: 1$<smiles>[X]c1c(OC)cccc1-n1cc(S(C)(=O)=O)nn1</smiles>

3f $70 \%(6 \mathrm{~h})$

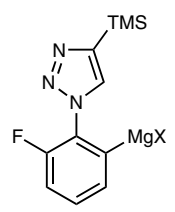

3g $80 \%$ (3 h)<smiles>COc1ccc(-c2cc(Cl)ccc2-n2cc(C)nn2)cc1</smiles><smiles>CS(=O)(=O)c1cn(-c2ccccc2-c2cccc(C3OCCO3)c2)nn1</smiles><smiles>CS(=O)(=O)c1cn(-c2ccc(Cl)cc2-c2ccc(C#N)c(F)c2)nn1</smiles><smiles>CS(C)(C)(C)(C)c1ccc(-c2cccc(F)c2-n2cc(F)c(C#N)c2)nn1</smiles><smiles>CCOC(=O)c1cccc(-c2cc(Cl)ccc2-n2cc(C)nn2)c1</smiles><smiles>Cc1cn(-c2ccc(F)cc2-c2cccc3ccccc23)nn1</smiles><smiles>CCCCOc1ccc(-c2cc(F)ccc2-n2cc(S(C)(=O)(O)C(C)(C)C)nn2)cc1</smiles><smiles>Cc1cn(-c2ccc(F)cc2-c2ccc([S-](F)(F)F)cc2)nn1</smiles><smiles>COc1ccc(-n2cc(S(C)(=O)=O)nn2)c(-c2cccc(C(F)(F)F)c2)c1</smiles><smiles>CS(=O)(=O)c1cn(-c2ccc(Cl)cc2-c2ccccc2F)nn1</smiles>

1k $71 \%$<smiles>CS(=O)(=O)c1cn(-c2ccc(Cl)cc2-c2cncnc2)nn1</smiles>

1n $62 \%$

1i $95 \%$<smiles>COc1cccc(-n2cc(C(C)(C)C)nn2)c1-c1ccc2c(ccn2C)c1</smiles>

$1084 \%$ 1j $70 \%$<smiles>COc1ccc(-n2cc(C)nn2)c(-c2ccc3sccc3c2)c1</smiles>

1 p $89 \%$<smiles></smiles>

1q $65 \%$<smiles>Nc1cccc(-c2cc(O)ccc2-n2cccc2)c1</smiles>

$1184 \%$<smiles>CS(=O)(=O)c1cn(-c2ccc(Cl)cc2-c2ccsc2)nn1</smiles>

1r $96 \%$<smiles>Nc1cccc(-c2cc(N)ccc2-n2cccc2)c1</smiles>

1 m $69 \%$

Fig. 3 Metalation of various aryl triazole derivatives and scope of the subsequent palladium-catalyzed cross-coupling. Experiments were performed on a $0.5 \mathrm{mmol}$ scale. ${ }^{[a]}$ Metalation yields were determined by ${ }^{1} \mathrm{H}-\mathrm{NMR}$ analysis of $\mathrm{D}_{2} \mathrm{O}$-quenched reaction aliquots. Metalation time in brackets. ${ }^{[b]} \mathrm{Metalation}$ ratio in $[\%]$ between regioisomers of type $A$ and $B .{ }^{[c]}$ All yields refer to isolated compounds. ${ }^{[d]}$ Reaction performed on a 5 mmol scale.

Mechanistic probes. We then sought to gain a deeper understanding of the metalation and cross-coupling steps. It is known that commercially available $\mathrm{Bu}_{2} \mathrm{Mg}$ solutions are mixtures of $n$ butyl and $s$-butyl magnesium species. Analysis of an iodolyzed sample revealed a $60: 40$ ratio of $n$-butyl and $s$-butyl moieties present in $\mathrm{Bu}_{2} \mathrm{Mg}$, and the same ratio was found in TMPMgBu . Interestingly, $\mathrm{Bu}_{2} \mathrm{Mg}$ in toluene/hexane was also an excellent base to selectively deprotonate $\mathbf{2 a}$ affording ortho-magnesiation in 93\% yield (Fig. 6). The resulting mixture mainly contained $\mathrm{ArMg}$ $(n-\mathrm{Bu})$ and $\operatorname{ArMg}(s-\mathrm{Bu})(89 \%$ and $4 \%$, respectively). However, after transmetalation with zinc chloride, only $28 \%$ of the desired cross-coupling product $\mathbf{1 b}$ were obtained together with $88 \%$ of 4 butyl-anisole (13a), resulting from the cross-coupling of the $n$ butyl residue. This observation accounts for the superiority of
$\mathrm{TMPMgBu}$ to $\mathrm{Bu}_{2} \mathrm{Mg}$ in the metalation/cross-coupling sequence: the use of TMPMgBu limits the formation of the ArMgBu and thus after transmetalation ArZnBu, which preferentially transfers the butyl group to $\mathrm{Ar}^{\prime} \mathrm{Br}$, forming the byproduct $\mathrm{Ar}^{\prime} \mathrm{Bu} 13 \mathbf{a}$.

\section{Discussion}

In conclusion, we have described a highly regioselective magnesiation of various aryl azoles using a hindered mixed magnesium amide base, TMPMgBu, in toluene/hexane at room temperature. Subsequent palladium-catalyzed cross-couplings with a variety of (hetero)aryl bromides or trapping with electrophiles afforded polyfunctionalized aryl azoles in good to excellent yields. This methodology could be applied to the synthesis of a key API 
a<smiles>[R]c1ccc(C2=[V]CCCN2)cc1</smiles>

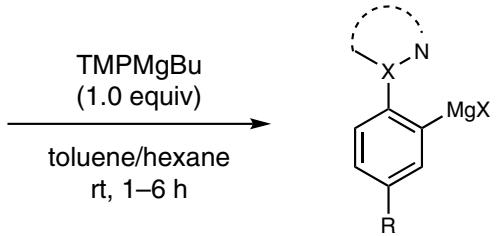

$5 a-d^{[a]}$<smiles>[R]c1ccc([Al]2CCCCN2)c(I)c1</smiles>

$6 a-h^{[b]}$<smiles>[X]c1cc(Cl)ccc1-n1nc(C)cc1C</smiles>

5 a $82 \%[c](1 \mathrm{~h})$<smiles>[X]c1ccccc1-c1nnc(-c2ccccc2)o1</smiles>

5c 76\% (2 h)<smiles>Cc1cc(C)n(-c2ccc(Cl)cc2-c2ccc3c(c2)OCO3)n1</smiles><smiles>Cc1cc(C)n(-c2ccc(Cl)cc2-c2cccnc2)n1</smiles><smiles>[X]c1cc(Cl)ccc1-n1cccn1</smiles>

5b $78 \%[c],[d](1 \mathrm{~h})$<smiles>CC(C)(C)O[Na]</smiles><smiles>N#Cc1ccc(-c2cc(Cl)ccc2-n2cccn2)cc1F</smiles>

bb $68 \%$<smiles>[X]c1ccccc1C1=NC(C)(C)CO1</smiles>

5d $77 \%(1 \mathrm{~h})$<smiles>CCOC(=O)c1cccc(-c2ccccc2-c2nnc(-c3ccccc3)o2)c1</smiles><smiles>CC1(C)COC(c2ccccc2-c2ccc(C(F)(F)F)cc2)=N1</smiles><smiles>CC1(C)COC(c2ccccc2-c2ccc3c(ccn3S(=O)(=O)[O-])c2)=N1</smiles>

6h $91 \%$

b<smiles>Cc1cn(-c2ccc(Cl)cc2)nn1</smiles>

$2 a$<smiles>CS(=O)(=O)c1cn(-c2ccc(Cl)cc2I)nn1</smiles>

7a $98 \%[\mathrm{e}]$ $73 \%$ [f]<smiles>[X]c1cc(Cl)ccc1-n1cc(C)nn1</smiles><smiles>Cc1cn(-c2ccc(Cl)cc2F)nn1</smiles>

3a $81 \%[a]$

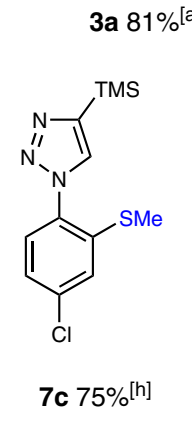

7c $75 \%$ [h]<smiles>CS(=O)(=O)c1cn(-c2ccc(Cl)cc2C(=O)c2ccccc2)nn1</smiles>

7d 62\% ${ }^{[i]}$<smiles>CS(=O)(=O)c1cn(-c2ccc(Cl)cc2C(O)c2ccccc2)nn1</smiles>

7b $86 \%[g]$
$7 a-e^{[b]}$<smiles>C=C(Cc1cc(Cl)ccc1-n1cc(S(C)(=O)=O)nn1)C(=O)OCC</smiles>

7e $77 \%[$ [i]

Fig. 4 Substrate scope of aryl azoles and electrophiles. a Metalation of various aryl triazole derivatives and scope of the subsequent palladium-catalyzed cross-coupling. ${ }^{[a]}$ Metalation yields were determined by ${ }^{1} \mathrm{H}-\mathrm{NMR}$ analysis of $\mathrm{D}_{2} \mathrm{O}$-quenched reaction aliquots. Metalation time in brackets. ${ }^{[b]} \mathrm{All}$ yields refer to isolated compounds. ${ }^{[c]}$ No metalation at the heterocycle was observed. [d]Performing the reaction with TMPLi exclusively led to metalation of the azole moiety. $\mathbf{b}$ Trapping of magnesium reagent $\mathbf{3 a}$ with various electrophiles. ${ }^{[e]} \mathrm{I}_{2}$ (4.3 equiv). ${ }^{[\mathrm{f}]}$ Metalation of $\mathbf{2} \mathbf{a}$ with $\mathrm{Bu}_{2} \mathrm{Mg}\left(\mathrm{vide}\right.$ infra), then $\mathrm{I}_{2}(4.3$ equiv). ${ }^{[g]}$ Benzaldehyde (2.5 equiv). ${ }^{[h]} \mathrm{MeSSO}_{2} \mathrm{Me}$ (2.5 equiv). ${ }^{[i]}$ Transmetalation with $\mathrm{CuCN} \bullet 2 \mathrm{LiCl}$ (3.0 equiv), then benzoyl chloride (2.5 equiv). [j] Transmetalation with $\mathrm{CuCN} \bullet 2 \mathrm{LiCl}$ (3.0 equiv), then ethyl 2-(bromomethyl)acrylate (2.5 equiv).

intermediate and several late-stage modifications demonstrated the versatility of the resulting products. Mechanistic experiments highlighted the key role of TMP for the reactivity of the resulting organomagnesium reagents in cross-coupling reactions.

\section{Methods}

Preparation of arylmagnesium reagent 3a. Aryl triazole $2 \mathbf{a}(126 \mathrm{mg}, 0.5 \mathrm{mmol}$, 1.0 equiv.) was placed in a dry and argon-flushed $10 \mathrm{ml}$ Schlenk tube equipped with a magnetic stirring bar and a septum and was suspended in toluene $(0.5 \mathrm{ml}, 1.00 \mathrm{M})$. TMPMgBu $(0.67 \mathrm{ml}, 0.75 \mathrm{M}, 1.0$ equiv) was added and the mixture was stirred for $1 \mathrm{~h}$ affording the magnesium reagent $3 \mathrm{a}$ in $81 \%$ yield.

Palladium-catalyzed cross-coupling. 3a was transmetalated with a $\mathrm{ZnCl}_{2}$ solution $(0.5 \mathrm{ml}, 1.00 \mathrm{M}$ in THF) and THF $(1.0 \mathrm{ml})$ was added. A dry and argonflushed Schlenk tube, equipped with a magnetic stirring bar and a septum, was charged with $\mathrm{Pd}(\mathrm{dppf}) \mathrm{Cl}_{2}(1.0 \mathrm{~mol} \%, 0.005 \mathrm{mmol}, 3.7 \mathrm{mg})$ and 1-bromo-4methoxybenzene $(0.850 \mathrm{mmol}, 159 \mathrm{mg}, 2.10$ equiv) was added. The freshly 


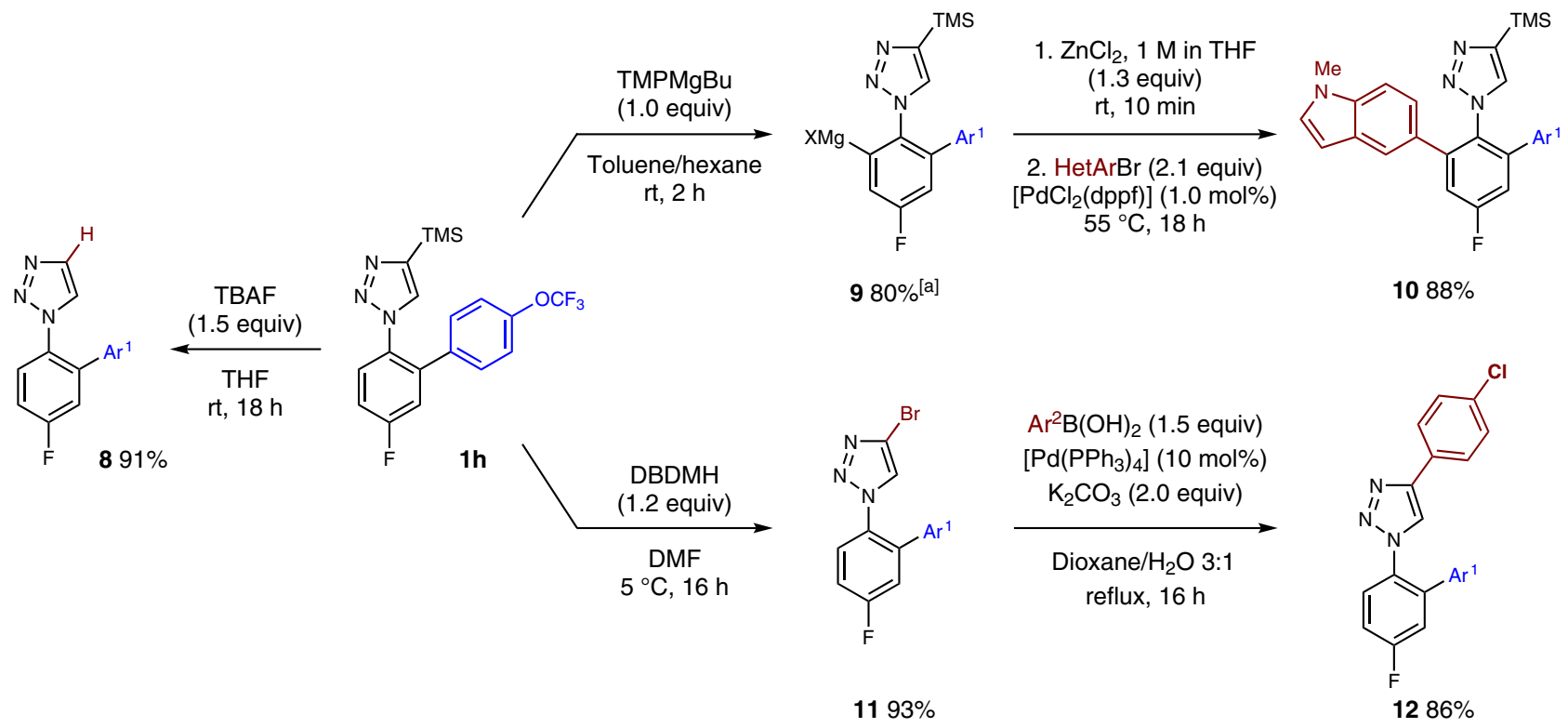

Fig. 5 Late-stage modifications. ${ }^{[a]}$ Metalation yields was determined by ${ }^{1} \mathrm{H}-\mathrm{NMR}$ analysis of $\mathrm{D}_{2} \mathrm{O}$-quenched reaction aliquots. All other yields refer to isolated compounds. HetAr $=\mathrm{N}-\mathrm{Me}-5$-indolyl, $\mathrm{Ar}^{1}=4-\mathrm{OCF}_{3}-\mathrm{C}_{6} \mathrm{H}_{4}, \mathrm{Ar}^{2}=4-\mathrm{Cl}_{6} \mathrm{C}_{6} \mathrm{H}_{4}$.<smiles>CSc1cn(-c2ccc(Cl)cc2)nn1</smiles>

2a

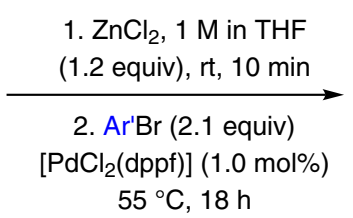

$55^{\circ} \mathrm{C}, 18 \mathrm{~h}$<smiles>COc1ccc(-c2cc(Cl)ccc2-n2cc(S(C)(=O)=O)nn2)cc1</smiles>

1b $28 \%$<smiles>COc1ccc(P)cc1</smiles>

13a $\mathrm{R}=n-\mathrm{Bu}: 88 \%$

13b $\mathrm{R}=s-\mathrm{Bu}: 4 \%$

$\mathrm{Bu}=$ mixture of $n-\mathrm{Bu}$ and $s-\mathrm{Bu}(60: 40)$<smiles>CSc1cn(-c2ccc(Cl)cc2)nn1</smiles>

2a

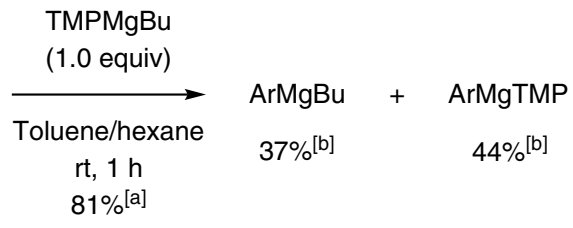

rt, $1 \mathrm{~h}$
1. $\mathrm{ZnCl}_{2}, 1 \mathrm{M}$ in $\mathrm{THF}$ (1.2 equiv), rt, $10 \mathrm{~min}$

2. $\operatorname{Ar} \mathrm{Br}$ (2.1 equiv)

$\left[\mathrm{PdCl}_{2}\right.$ (dppf)] (1.0 mol\%) $55^{\circ} \mathrm{C}, 18 \mathrm{~h}$<smiles>COc1ccc(-c2cc(Cl)ccc2-n2cc(C)nn2)cc1</smiles>

1b $84 \%$<smiles>COc1ccc(P)cc1</smiles>

13a $\mathrm{R}=n-\mathrm{Bu}: 28 \%$

13b R $=s-\mathrm{Bu}: 4 \%$

Fig. 6 Mechanistic probes. [a] Metalation yields were determined by ${ }^{1} \mathrm{H}-\mathrm{NMR}$ analysis of $\mathrm{D}_{2} \mathrm{O}$-quenched reaction aliquots. [b] Yields were determined by $\mathrm{GC}$ analysis of iodolyzed aliquots using undecane as an internal standard. $\mathrm{Ar}=5-\mathrm{Cl}-2-(4-\mathrm{TMS}-1 \mathrm{H}-1,2,3-\operatorname{triazol}-1-\mathrm{yl})-\mathrm{C}_{6} \mathrm{H}_{3} . \mathrm{Ar}^{\prime}=4-\mathrm{MeO}^{-} \mathrm{C}_{6} \mathrm{H}_{4}$.

prepared arylzinc reagent was added and the reaction mixture was placed in an oil bath at $55^{\circ} \mathrm{C}$. After $16 \mathrm{~h}$, saturated aq. $\mathrm{NH}_{4} \mathrm{Cl}$ solution $(5 \mathrm{ml})$ was added, the phases were separated, and the aqueous phase was extracted with EtOAc $(3 \times 25$ $\mathrm{ml}$ ). The combined organic layers were dried over $\mathrm{MgSO}_{4}$. The solvents were removed under reduced pressure and the crude product was subjected to column chromatography.

\section{Data availability}

The authors declare that the data supporting the findings of this study are available within the paper and its Supplementary Information files.

Received: 14 May 2020; Accepted: 3 August 2020;

Published online: 07 September 2020

\section{References}

1. Penning, T. D. et al. Synthesis and biological evaluation of the 1,5diarylpyrazole class of cyclooxygenase-2 inhibitors: identification of 4-[5-(4methylphenyl)-3-(trifluoromethyl)-1H-pyrazol-1-yl]benzenesulfonamide (SC58635, Celecoxib). J. Med. Chem. 40, 1347-1365 (1997).

2. Pinto, D. J. P. et al. Discovery of 1-(4-methoxyphenyl)-7-oxo-6-(4-(2oxopiperidin-1-yl)phenyl)-4,5,6,7-tetrahydro-1H-pyrazolo[3,4-c]pyridine-3carboxamide (Apixaban, BMS-562247), a highly potent, selective, efficacious, and orally bioavailable inhibitor of blood coagulation factor Xa. J. Med. Chem. 50, 5339-5356 (2007)

3. Tomkinson, H. et al. Pharmacokinetics and tolerability of zibotentan (ZD4054) in subjects with hepatic or renal impairment: two open-label comparative studies. BMC Clin. Pharmacol. 11, 3 (2011).

4. Schlecker, R. \& Thieme, P. C. The synthesis of antihypertensive 3-(1,3,4oxadiazol-2-yl)phenoxypropanolahines. Tetrahedron 44, 3289-3294 (1988). 
5. Ayothiraman, R. et al. Two approaches to a trifluoromethyl triazole: a fit-forpurpose trifluoromethylation in flow-mode and a long-term decarboxylative click approach. Org. Process Res. Dev. 24, 207-215 (2020).

6. Alberico, D., Scott, M. E. \& Lautens, M. Aryl-aryl bond formation by transition-metal-catalyzed direct arylation. Chem. Rev. 107, 174-238 (2007).

7. Ackermann, L. Catalytic arylations with challenging substrates: from air-stable haspo preligands to indole syntheses and C-H-bond functionalizations. Synlett 2007, 507-526 (2007).

8. Arockiam, P. B., Bruneau, C. \& Dixneuf, P. H. Ruthenium(II)-catalyzed C-H bond activation and functionalization. Chem. Rev. 112, 5879-5918 (2012).

9. Kuhl, N., Schröder, N. \& Glorius, F. Formal SN-type reactions in Rhodium(III)catalyzed C-H bond activation. Adv. Synth. Catal. 356, 1443-1460 (2014).

10. Yang, Y., Lan, J. \& You, J. Oxidative C-H/C-H coupling reactions between two (Hetero)arenes. Chem. Rev. 117, 8787-8863 (2017).

11. Gandeepan, P. et al. $3 \mathrm{~d}$ transition metals for C-H sctivation. Chem. Rev. 119, 2192-2452 (2019).

12. Oi, S., Aizawa, E., Ogino, Y. \& Inoue, Y. Ortho-selective direct cross-coupling reaction of 2-aryloxazolines and 2-arylimidazolines with aryl and alkenyl halides catalyzed by ruthenium complexes. J. Org. Chem. 70, 3113-3119 (2005).

13. Ackermann, L., Althammer, A. \& Born, R. $\left[\mathrm{RuCl}_{3}\left(\mathrm{H}_{2} \mathrm{O}\right)_{n}\right]$-catalyzed direct arylations with bromides as electrophiles. Synlett 2007, 2833-2836 (2007).

14. Oi, S., Sasamoto, H., Funayama, R. \& Inoue, Y. Ortho-selective arylation of arylazoles with aryl bromides catalyzed by ruthenium complexes. Chem. Lett. 37, 994-995 (2008)

15. Simonetti, M. et al. Cyclometallated ruthenium catalyst enables late-stage directed arylation of pharmaceuticals. Nat. Chem. 10, 724-731 (2018).

16. Ackermann, L., Althammer, A. \& Born, R. [RuCl3(H2O)n]-catalyzed direct arylations. Tetrahedron 64, 6115-6124 (2008).

17. Kwak, S. H., Gulia, N. \& Daugulis, O. Synthesis of unsymmetrical 2,6diarylanilines by palladium-catalyzed $\mathrm{C}-\mathrm{H}$ bond functionalization methodology. J. Org. Chem. 83, 5844-5850 (2018).

18. Oi, S., Sato, H., Sugawara, S. \& Inoue, Y. Nitrogen-directed ortho-selective homocoupling of aromatic compounds catalyzed by ruthenium complexes. Org. Lett. 10, 1823-1826 (2008).

19. Ackermann, L., Born, R. \& Vicente, R. Ruthenium-catalyzed direct arylations of $\mathrm{N}$-aryl 1,2,3-triazoles with aryl chlorides as electrophiles. ChemSusChem 2, 546-549 (2009).

20. Teskey, C. J. et al. Domino N-/C-arylation via in situ generation of a directing group: atom-efficient arylation using diaryliodonium salts. Angew. Chem. Int. Ed. 56, 5263-5266 (2017).

21. Ackermann, L., Vicente, R. \& Althammer, A. Assisted ruthenium-catalyzed $\mathrm{C}-\mathrm{H}$ bond activation: carboxylic acids as cocatalysts for generally applicable direct arylations in apolar solvents. Org. Lett. 10, 2299-2302 (2008).

22. Daugulis, O. \& Zaitsev, V. G. Anilide ortho-arylation by using C-H activation methodology. Angew. Chem. Int. Ed. 44, 4046-4048 (2005).

23. Oi, S., Funayama, R., Hattori, T. \& Inoue, Y. Nitrogen-directed orthoarylation and -heteroarylation of aromatic rings catalyzed by ruthenium complexes. Tetrahedron 64, 6051-6059 (2008).

24. Ballesteros-Garrido, R. et al. The deprotonative metalation of $[1,2,3]$ triazolo [1,5-a]quinoline. Synthesis of 8-haloquinolin-2-carboxaldehydes. Tetrahedron 65, 4410-4417 (2009).

25. Whisler, M. C., MacNeil, S., Snieckus, V. \& Beak, P. Beyond thermodynamic acidity: a perspective on the complex-induced proximity effect (CIPE) in deprotonation reactions. Angew. Chem. Int. Ed. 43, 2206-2225 (2004).

26. Haag, B. et al. Regio- and chemoselective metalation of arenes and heteroarenes using hindered metal amide bases. Angew. Chem. Int. Ed. 50, 9794-9824 (2011).

27. Balkenhohl, M. \& Knochel, P. Regioselective C-H activation of substituted pyridines and other azines using Mg- and Zn-TMP-bases. SynOpen 02, 78-95 (2018).

28. Lutter, F. H. et al. In Organic Reactions (ed. Denmark, S. E.) (Wiley, 2019).

29. Ziegler, D. S. et al. Directed zincation or magnesiation of the 2-pyridone and 2,7-naphthyridone scaffold using TMP bases. Org. Lett. 19, 5760-5763 (2017).

30. Balkenhohl, M. et al. Zn-, Mg-, and Li-TMP bases for the successive regioselective metalations of the 1,5-naphthyridine scaffold (TMP=2,2,6,6tetramethylpiperidyl). Chem. Eur. J. 23, 13046-13050 (2017).

31. Boga, S. B. et al. Selective functionalization of complex heterocycles via an automated strong base screening platform. React. Chem. Eng. 2, 446-450 (2017).

32. Balkenhohl, M. et al. Regioselective metalation and functionalization of the pyrazolo[1,5-a]pyridine scaffold using $\mathrm{Mg}$ - and $\mathrm{Zn}$-TMP bases. Org. Lett. 20, 3114-3118 (2018).

33. Balkenhohl, M. et al. Lewis acid directed regioselective metalations of pyridazine. Angew. Chem. Int. Ed. 58, $9244-9247$ (2019).

34. Hlavinka, M. L. \& Hagadorn, J. R. $\mathrm{Zn}(\operatorname{tmp})_{2}$ : a versatile base for the selective functionalization of $\mathrm{C}-\mathrm{H}$ bonds. Organometallics 26, 4105-4108 (2007).

35. Hlavinka, M. L. \& Hagadorn, J. R. One-step deprotonation route to zinc amide and ester enolates for use in aldol reactions and Negishi couplings. Tetrahedron Lett. 47, 5049-5053 (2006).
36. Blair, V. L. et al. Tuning the basicity of synergic bimetallic reagents: switching the regioselectivity of the direct dimetalation of toluene from 2,5- to 3,5positions. Angew. Chem. Int. Ed. 47, 6208-6211 (2008).

37. Martínez-Martínez, A. J. et al. Templated deprotonative metalation of polyaryl systems: facile access to simple, previously inaccessible multi-iodoarenes. Sci. Adv. 3, e1700832 (2017).

38. Martínez-Martínez, A. J. et al. Pre-inverse-crowns: synthetic, structural and reactivity studies of alkali metal magnesiates primed for inverse crown formation. Chem. Sci. 5, 771-781 (2014).

39. Mulvey, R. E. Modern ate chemistry: applications of synergic mixed alkalimetal-magnesium or -zinc reagents in synthesis and structure building. Organometallics 25, 1060-1075 (2006).

40. Martínez-Martínez, A. J., Kennedy, A. R., Mulvey, R. E. \& O’Hara, C. T. Directed ortho-metá- and meta-meta-dimetalations: a template base approach to deprotonation. Science 346, 834 (2014).

41. Robertson, S. D., Uzelac, M. \& Mulvey, R. E. Alkali-metal-mediated synergistic effects in polar main group organometallic chemistry. Chem. Rev. 119, 8332-8405 (2019).

42. Stevens, M. A. et al. Contrasting synergistic heterobimetallic (Na-Mg) and homometallic $(\mathrm{Na}$ or $\mathrm{Mg})$ bases in metallation reactions of dialkylphenylphosphines and dialkylanilines: lateral versus ring selectivities. Chem. Eur. J. 24, 15669-15677 (2018)

43. Fuentes, M. Á., Zabala, A., Kennedy, A. R. \& Mulvey, R. E. Structural diversity in alkali metal and alkali metal magnesiate chemistry of the bulky 2,6diisopropyl-N-(trimethylsilyl)anilino ligand. Chem. Eur. J. 22, 14968-14978 (2016).

44. Eaton, P. E., Lee, C. H. \& Xiong, Y. Magnesium amide bases and amidogrignards. 1. Ortho magnesiation. J. Am. Chem. Soc. 111, 8016-8018 (1989)

45. Eaton, P. E., Xiong, Y. \& Gilardi, R. Systematic substitution on the cubane nucleus. Synthesis and properties of 1,3,5-trinitrocubane and 1,3,5,7tetranitrocubane. J. Am. Chem. Soc. 115, 10195-10202 (1993).

46. Ooi, T., Uematsu, Y. \& Maruoka, K. New, improved procedure for the synthesis of structurally diverse $\mathrm{N}$-spiro C2-symmetric chiral quaternary ammonium bromides. J. Org. Chem. 68, 4576-4578 (2003).

47. Hevia, E., Kennedy, A. R., Mulvey, R. E. \& Weatherstone, S. Synthesis and crystal structure of $\left[\{n \mathrm{BuMg}(\mu-\mathrm{TMP})\}_{2}\right]$ and of a homometallic inverse crown in tetranuclear $\left[\left\{n \mathrm{BuMg}_{2}[\mu-N(H) \mathrm{Dipp}] 2\left(\mu_{3}-\mathrm{OnBu}\right)\right\}_{2}\right]$. Angew. Chem. Int. Ed. 43, 1709-1712 (2004).

48. Conway, B. et al. Synthesis and characterisation of a series of alkylmagnesium amide and related oxygen-contaminated "alkoxy" compounds. Dalton Trans. 2005, 1532-1544 (2005)

49. Feldmann, J. et al. Blue luminescent compounds, US 20150236278 A1 (2015)

\section{Acknowledgements}

We thank Janssen Pharmaceutica and Bristol-Myers Squibb for the funding of the project. We thank the Deutsche Forschungsgemeinschaft (DFG) and the LudwigMaximilians-Universität München for financial support. We also thank Albemarle Lithium GmbH (Hoechst, Frankfurt) for the generous gift of chemicals.

\section{Author contributions}

F.H.L., L.G., and L.A.P. performed and analyzed the experiments F.H.L., D.B., S.L., S.W., and P.K. designed the experiments. F.H.L., L.A.P., S.W., and P.K. prepared the manuscript with contributions of all authors.

\section{Funding}

Open Access funding provided by Projekt DEAL.

\section{Competing interests}

The authors declare no competing interests.

\section{Additional information}

Supplementary information is available for this paper at https://doi.org/10.1038/s41467020-18188-z.

Correspondence and requests for materials should be addressed to S.W. or P.K.

Peer review information Nature Communications thanks Melodie Christensen, Matthieu Tissot and the other, anonymous, reviewer(s) for their contribution to the peer review of this work. Peer reviewer reports are available.

Reprints and permission information is available at http://www.nature.com/reprints

Publisher's note Springer Nature remains neutral with regard to jurisdictional claims in published maps and institutional affiliations. 
(c) (i) Open Access This article is licensed under a Creative Commons Attribution 4.0 International License, which permits use, sharing, adaptation, distribution and reproduction in any medium or format, as long as you give appropriate credit to the original author(s) and the source, provide a link to the Creative Commons license, and indicate if changes were made. The images or other third party material in this article are included in the article's Creative Commons license, unless indicated otherwise in a credit line to the material. If material is not included in the article's Creative Commons license and your intended use is not permitted by statutory regulation or exceeds the permitted use, you will need to obtain permission directly from the copyright holder. To view a copy of this license, visit http://creativecommons.org/ licenses/by/4.0/.

(C) The Author(s) 2020 